\title{
Topical treatment of genital warts in men, an open study of podophyllotoxin cream compared with solution
}

\author{
A Strand, R-M Brinkeborn, A Siboulet
}

\begin{abstract}
Objective-To evaluate the clinical efficacy of a $0 \cdot 15 \%$ and a $0 \cdot 3 \%$ cream formulation of podophyllotoxin in comparison with the $0.5 \%$ solution in the treatment of condylomata acuminata and to compare the treatment modalities regarding side effects.

Design-The study was designed as an open randomised trial. Ninety male patients with signs of penile HPV infection, with either acuminate or papular lesions, were randomised into three parallel treatment groups. The study medication comprised $0.15 \%$ and $0.3 \%$ cream and $0.5 \%$ solution of podophyllotoxin. The patients treated themselves twice daily for three consecutive days and if total regression of the warts was not achieved after this first treatment cycle, further treatment cycles at 7-day intervals were to be repeated up to a maxi-
\end{abstract} mum of four treatments.

Setting-The study was carried out in three outpatient clinics: two STD clinics, Department of Dermatology and Venereology, University Hospital (45 patients) and Institut Antoine Fournier, Paris (30 patients), and one military hospital, S1/FO 47/48, Sjukhusenheten, Enköping (15 patients).

Results-Statistical evaluation of the treatment effect was based on a "Response rate" calculation at each visit. The number of completely responding patients after the first, second, third and fourth cycle were 40 (44\%), 61 (68\%), 67 (74\%) and $70(78 \%)$, respectively. There was no statistically significant difference between the three treatments after four treatment cycles. However, the $0.15 \%$ cream had a significantly slower onset of efficacy as compared with the $0.3 \%$ cream and $0.5 \%$ solution. Adverse effects were less severe and less frequent with the $0 \cdot 15 \%$ cream than with the other treatment modalities. Severe adverse effects were reported by 12 patients, of whom two were treated with $0.15 \%$ cream, five with $0.3 \%$ cream and five with $0.5 \%$ solution. Thirty-one patients were completely free from adverse effects.

Conclusion-In this open randomised study with three parallel treatment groups, two cream formulations of $0 \cdot 15 \%$ and $0.3 \%$ podophyllotoxin and $a \cdot 0.5 \%$ solution of the same drug all showed an equally good response rate after four treatment cycles. Reported adverse effects were few and mild. The convenience of having different formulations to offer when prescribing treatment for condylomata must be considered.

(Genitourin Med 1995;71:387-390)

Keywords: genital warts; podophyllotoxin cream; men

\section{Introduction}

In disciplines treating sexually transmitted diseases (STDs) the last decade has been a challenge. A shift from curable infections such as gonorrhoea, chlamydia and syphilis towards treatable but incurable viral diseases such as infections with HPV, HSV and HIV has changed the scene substantially.

Human papilloma virus (HPV) infection is today the most prevalent STD in western countries and accounts for up to $25 \%$ of the total attendances in genitourinary medicine (GUM) clinics in the United Kingdom. ${ }^{1}$ Topical application of podophyllin is widely prescribed, although more sophisticated drugs such as interferon have been tried in difficult cases, as well as surgical treatment. Podophyllin, a crude and non-standardised plant extract, has significant local and systemic toxicity. The use of podophyllin may be complicated by severe erosions of the mucus membranes, and patients occasionally have to be hospitalised after such treatment. ${ }^{2}$ Because of these side effects, applications of podophyllin should be carried out by a physician or a nurse, which places a heavy work load on the medical staff. ${ }^{3}$ Podophyllotoxin, the main active component of podophyllin, is a purer and more stable product than podophyllin and has a longer shelf-life. Several studies carried out by von Krogh and others have documented the cost-benefit of $0.5 \%$ podophyllotoxin-ethanol treatment applied by the patient twice daily for three days, ${ }^{45}$ and this has now become the treatment of choice both for female and male patients in the initial treatment of condyloma acuminata. ${ }^{6}$

A podophyllotoxin solution can sometimes be difficult to apply and a cream formulation has long been requested by both physicians and patients. Women may especially benefit from a cream formulation, since it is easier to apply the cream with a finger than to apply the solution, for which an applicator must be used. ${ }^{7}$ 
Table 1 Patient characteristics at study entry

\begin{tabular}{|c|c|c|c|}
\hline \multirow[b]{2}{*}{ Characteristics } & \multicolumn{3}{|l|}{ Treatment groups } \\
\hline & $\begin{array}{l}\text { Podophyllotoxin } \\
\text { Cream } 0 \cdot 15 \% \\
(n=30)\end{array}$ & $\begin{array}{l}\text { Cream } 0 \cdot 3 \% \\
(n=31)\end{array}$ & $\begin{array}{l}\text { Solution } 0.5 \% \\
(n=29)\end{array}$ \\
\hline \multicolumn{4}{|l|}{ Age } \\
\hline -mean (years) & $25 \cdot 7$ & $27 \cdot 2$ & $27 \cdot 5$ \\
\hline \multicolumn{4}{|l|}{ Mean duration of lesions (months) } \\
\hline -mean & $2 \cdot 5$ & $2 \cdot 5$ & $2 \cdot 6$ \\
\hline -range & $0 \cdot 4-5 \cdot 5$ & $0 \cdot 7-5 \cdot 6$ & $0 \cdot 6-4 \cdot 9$ \\
\hline \multicolumn{4}{|l|}{ Number of warts } \\
\hline -mean & $6 \cdot 9$ & $7 \cdot 0$ & $7 \cdot 9$ \\
\hline -range & $1-23$ & $1-32$ & $1-27$ \\
\hline No (\%) with previously treated condylomata & $5(16 \cdot 6 \%)$ & $5(16 \cdot 1 \%)$ & $6(20 \cdot 7 \%)$ \\
\hline No $(\%)$ with previous STDs & $7(23 \cdot 3 \%)$ & $13(41.9 \%)$ & $10(34 \cdot 5 \%)$ \\
\hline No $(\%)$ with regular partner & $19(63.3 \%)$ & $17(54 \cdot 8 \%)$ & $18(62 \cdot 1 \%)$ \\
\hline
\end{tabular}

In this study the efficacy of two concentrations of podophyllotoxin cream, $0 \cdot 15 \%$ and $0.3 \%$, was compared with the standard treatment, the $0.5 \%$ solution, in patients with HPV infection. The response rate and any local side effects were recorded.

\section{Patients and methods}

The study comprised 88 white and two black male heterosexual patients with condylomata, acuminate or papular. Other STDs were screened for and treated before the patients were randomised to the treatment groups. Only HIV negative patients were included in the study.

The study was designed as an open randomised trial with three parallel groups, with 30 patients in the $0.15 \%$ podophyllotoxin cream group, 31 in the $0.3 \%$ podophyllotoxin cream group and 29 in the $0.5 \%$ podophyllotoxin solution group. Some demographic data are shown in table 1 . The ages of the patients ranged between 18 and 48 years, with mean ages of 27, 26 and 28 years in the above three treatment groups, respectively. The mean durations of the condylomata in these three respective groups were $2.5,2.5$ and 2.6 months.

The treatment groups were comparable with regard to baseline values with respect to age, duration of lesions, number of lesions, proportions with previously treated STDs and proportions with a regular partner. Totally 16 patients had previously been treated for condylomata. Men under 18 years of age were excluded. Other exclusion criteria were a duration of the present lesions of more than three months, and the presence of intra-anal or anal condylomata, and previous treatment within three months.

The diagnosis was based on clinical examination, and no biopsy specimens for histological examination and HPV detection were obtained. The patients were followed up by the same doctor throughout the study. The patients were informed about the purpose of the study and possible side effects, and that participation was voluntary. All gave their informed consent. The study was approved by the local ethics committee at the Akademiska Hospital and the patients were enrolled and treated at the STD Clinic of the Akademiska
Hospital, Uppsala, Institut Alfred Fournier, Paris, or the Military Hospital, Enköping between January 1990 and January 1991.

The cream preparations of podophyllotoxin consisted of an oil phase blended into a purified water phase, with $75 \%$ water and $25 \%$ oil phase comprising propylene glycol, cetyl alcohol, isopropyl myristate, liquid paraffin and fractionated coconut oil. Methyl-p-hydroxybenzoate and sorbic acid (Merck) were used as preservatives. The $0.5 \%$ podophyllotoxin solution contained $5.0 \mathrm{mg}$ podophyllotoxin blended with $640 \mathrm{mg} 70 \%$ ethanol, $0.5 \mathrm{mg}$ methylrosaniline as colour indicator, purified water and phosphoric acid, $\mathrm{pH}$. The patients were instructed to apply the solution with an applicator and the cream with a finger twice daily for a period of three days, which was defined as one treatment cycle. A clinical evaluation was performed on the 7th day, that is, on the fourth day after termination of the first treatment cycle and also after any subsequent treatment cycles. The patients were treated until complete cure of the condylomata had been achieved or for a maximum of 4 weeks ( 4 treatment cycles). If four treatment cycles did not result in a complete cure, this was regarded as a treatment failure. The patients returned for a relapse examination 16 weeks after entry into the study.

Patients regarded as complete responders at any time of the trial were scheduled to return for the relapse examination at week 16 . Any relapse prior to that visit was to be reported to the investigator immediately. At each visit, I to VI, that is, the initial visit, the visits after the four treatment cycles, and the relapse examination, a detailed inspection with delineation and depiction on a chart was carried out.

The statistical evaluation of the treatment effect was based on a "response rate" calculated in the individual patient by using the formula: response rate $=100 \times[\mathrm{C} /(\mathrm{C}+\mathrm{N})]$, where $C=$ the number of warts cured since the start of the study and $\mathrm{N}=$ number of initial warts that did not change. The response rate was calculated at each visit for each patient.

\section{Results}

The primary response rates from the different treatments are shown in table 2 . The response rate analysis showed no significant difference between the treatment effects except for the $0.15 \%$ cream group, in which at visit III there were fewer completely cured patients than in the other two groups. This may imply a slower onset of effect with the $0 \cdot 15 \%$ cream than with the other formulations.

After one week of treatment 40 patients displayed a complete response. The distribution among the three groups was $11 / 30(37 \%)$ in the $0.15 \%$ cream group, $14 / 31(45 \%)$ in the $0.3 \%$ cream group and $15 / 29(52 \%)$ in the $0.5 \%$ solution group.

The number of patients with a complete response had increased to $70 / 90(77 \cdot 8 \%)$ at visit $\mathrm{V}$. The numbers of completely responding patients in the above three groups were 
Table 2 Primary and permanent response rates after treatment twice daily 3 days a week with $0.15 \%$ or $0.3 \%$ podophyllotoxin cream or $0.5 \%$ podophyllotoxin solution

\begin{tabular}{|c|c|c|c|c|}
\hline \multirow[b]{2}{*}{ Response rates } & \multicolumn{4}{|l|}{ Treatment groups } \\
\hline & $\begin{array}{l}\text { Podophyllotoxin } \\
\text { Cream } 0 \cdot 15 \% \\
(n=30)\end{array}$ & $\begin{array}{l}\text { Cream } 0 \cdot 3 \% \\
(n=31)\end{array}$ & $\begin{array}{l}\text { Solution } 0 \cdot 5 \% \\
(n=29)\end{array}$ & $\begin{array}{l}\text { Total } \\
(n=90)\end{array}$ \\
\hline \multicolumn{5}{|l|}{ Primary response rate } \\
\hline First cycle & $11(37 \%)$ & $14(45 \%)$ & $15(52 \%)$ & $40(44 \%)$ \\
\hline Second cycle & $15(50 \%)$ & $23(74 \%)$ & $23(79 \%)$ & $61(68 \%)$ \\
\hline Third cycle & $20(67 \%)$ & $24(77 \%)$ & $23(79 \%)$ & $67(74 \%)$ \\
\hline Fourth cycle & $21(70 \%)$ & $25(81 \%)$ & $24(83 \%)$ & $70(78 \%)$ \\
\hline Non-responders & $3(10 \%)$ & $1(3 \%)$ & $2(7 \%)$ & $6(7 \%)$ \\
\hline $\begin{array}{c}\text { Recurrence } \\
16 \text { weeks }\end{array}$ & $4(13 \%)$ & $6(19 \%)$ & $5(17 \%)$ & $15(17 \%)$ \\
\hline Permanent response rate & $17(57 \%)$ & $21(68 \%)$ & $20(69 \%)$ & $55(61 \%)$ \\
\hline
\end{tabular}

$\star 11$ patients did not return for relapse examination.

now 21,25 and 24 respectively. Six patients did not respond to treatment at all-3 in the $0.15 \%$ cream group, 1 in the $0.3 \%$ cream group and 2 in the $0.5 \%$ solution group. Three of the six treatment failures occurred in patients who had previously been unsuccessfully treated for condylomata.

At the week 16 follow-up visit, recurrence of warts was seen in 15 out of the 90 patients $(16.6 \%)-4$ in the $0.15 \%$ group, 6 in the $0.3 \%$ group and 5 in the $0.5 \%$ group. Eleven patients $(12 \%)$ did not return for relapse examination. We are surprised at the small number of patients who failed to attend for this check-up; in many studies like these the compliance for the follow-up arrangement is poor. ${ }^{1}$ A permanent response, as evaluated at the week 16 follow-up, was found in 55/90 $(61 \%)$ of the evaluable cases. If only cases with true relapse warts, i.e. warts in previously treated areas, are considered, 12 patients $(13 \cdot 3 \%)$ had recurrences, giving a permanent response rate of $58 / 90(64 \cdot 4 \%)$.

Adverse effects were recorded as itching, a burning sensation, tenderness, pruritus, erythema, erosion and others. In view of the fact that podophyllotoxin is a chemodestructive agent, some adverse effects have to be accepted, if not severe. Most of these symptoms were mild to moderate and 31 of the patients $(34 \%)$ had no adverse effects whatsoever. Severe effects were reported by 12 patients, 2 in the $0.15 \%$ cream group and 5 each in the $0.3 \%$ cream and $0.5 \%$ solution group, with no significant difference. It is notable that no patient stopped treatment because of adverse effects.

\section{Discussion}

It is suggested by Reynolds $e a^{8}$ that in terms of efficacy, acceptability, convenience and cost, the need for standardised first-line treatment for condylomata is met in men by selfapplied podophyllotoxin. Since the only formulation on the market today is a liquid ethanol preparation which for women can be difficult to apply, a cream formulation could also make podophyllotoxin the treatment of first choice for non-pregnant women with condylomata.

With the high prevalence of HPV infection seen in STD clinics today, ${ }^{9}$ the possibility of offering home-based treatment with podophyllotoxin to both women and men seems to be a promising opportunity to lower the costs for both the patient and the health care system. Fewer appointments and, as shown in a study by Lassus, ${ }^{10}$ highly favourable long-term efficacy of podophyllotoxin as compared with podophyllin, should be taken into account. After a four-cycle treatment with weekly intervals, as in our study, a clearance rate of $100 \%$ was obtained by Lassus in a self-treatment group using podophyllotoxin, compared with a clearance rate of $71 \%$ in office-based treated patients who received podophyllin. Relapse was experienced by $23 \%$ of the podophyllotoxintreated patients as compared with $38 \%$ of those who received podophyllin. The relapse rate was estimated within 3 months.

Our results cannot compare with these very favourable results obtained by Lassus, but are more in accordance with those of Mazurkiewicz et $a{ }^{7}{ }^{7}$ who found that $68 \%$ of the patients were free from warts after four cycles of podophyllotoxin treatment.

In a recent report by Kinghorn et al, ${ }^{1}$ it was pointed out that the lower response to selfapplied podophyllotoxin in the treatment of external genital warts observed in women, compared with men, might be due to the difficulty encountered by women in applying a solution. A cream formulation would presumably be easier for women to apply and this could explain the good results achieved by von Krogh, who found a primary cure rate of $91 \%$ after 3 treatment cycles of self-applied $0.5 \%$ podophyllotoxin cream in the treatment of external genital condylomata acuminata in women. ${ }^{11}$ In that study the authors also calculated the efficacy from the total numbers of warts eradicated and noted a $98 \cdot 1 \%$ reduction after the third cycle of treatment with $0.5 \%$ podophyllotoxin cream.

In this study, if we consider the number of lesions that responded to treatment, the result is not really very good, but it is more favourable than when considering the number of individual patients responding. The mean number of lesions in each patient was 7-8, with a range from 1-32 (table 1). The total numbers of lesions at entry into the study in the patients receiving the $0.15 \%$ and $0.3 \%$ cream formulations were 217 and 220 respectively, and in those treated with the $0.5 \%$ solution, 229. Of these 666 lesions, 571 $(85 \cdot 7 \%)$ were successfully eradicated at the end of the study. In these three groups the wart clearance rates were $83.4 \%, 91.4 \%$ and $82.5 \%$ respectively (table 3 ). The $0.3 \%$ cream formulation gave the best response rate. Although there was no significant difference in efficacy between the three formulations of podophyllotoxin, we would recommend the $0.3 \%$ cream as an alternative to the $0.5 \%$ solution, as the $0 \cdot 15 \%$ cream appears to have a slower onset of action.

As noted by other investigators, the lesion site is of importance for the treatment response. ${ }^{1}$ The best result is observed after treatment on the glans penis and the prepuce, followed by the shaft and other sites. 
Table 3 Effect of therapy on lesions at various sites ( $n=$ number of patients)

\begin{tabular}{|c|c|c|c|c|c|c|}
\hline \multirow[b]{3}{*}{ Site of lesion } & \multicolumn{6}{|c|}{ Treatment groups } \\
\hline & \multicolumn{2}{|c|}{$\begin{array}{l}\text { Podophyllotoxin } \\
\text { Cream } 0 \cdot 15 \% \\
(n=30)\end{array}$} & \multicolumn{2}{|c|}{$\begin{array}{l}\text { Cream } 0 \cdot 3 \% \\
(n=31)\end{array}$} & \multicolumn{2}{|c|}{$\begin{array}{l}\text { Solution } 0.5 \% \\
(n=29)\end{array}$} \\
\hline & $\begin{array}{l}\text { Initial No } \\
\text { of lesions }\end{array}$ & $\begin{array}{l}\text { No of lesions } \\
\text { at visit } 5 \\
\text { (\% healed) }\end{array}$ & $\begin{array}{l}\text { Initial No } \\
\text { of lesions }\end{array}$ & $\begin{array}{l}\text { No of lesions } \\
\text { at visit } 5 \\
\text { (\% healed) }\end{array}$ & $\begin{array}{l}\text { Initial No } \\
\text { of lesions }\end{array}$ & $\begin{array}{l}\text { No of lesions } \\
\text { at visit } 5 \\
\text { (\% healed) }\end{array}$ \\
\hline $\begin{array}{l}\text { Prepuce } \\
\text { Glans } \\
\text { Shaft } \\
\text { Other }\end{array}$ & $\begin{array}{r}129 \\
43 \\
34 \\
11\end{array}$ & $\begin{array}{c}19(85 \cdot 3 \%) \\
3(93 \%) \\
10(70 \cdot 6 \%) \\
4(63 \cdot 6 \%)\end{array}$ & $\begin{array}{r}137 \\
61 \\
22 \\
-\end{array}$ & $\begin{array}{c}12(91 \cdot 2 \%) \\
0(100 \%) \\
7(68 \cdot 2 \%) \\
-\end{array}$ & $\begin{array}{r}139 \\
73 \\
8 \\
9\end{array}$ & $\begin{array}{r}32(77 \cdot 0 \%) \\
1(98 \cdot 6 \%) \\
1(87 \cdot 5 \%) \\
6(33 \cdot 0 \%)\end{array}$ \\
\hline Total sites & 217 & $36(83 \cdot 4 \%)$ & 220 & $19(91 \cdot 4 \%)$ & 229 & $40(82.5 \%)$ \\
\hline
\end{tabular}

In the present study good results were accomplished when treating penile condylomata with self-applied topical podophyllotoxin of different concentrations. In terms of efficacy, acceptability, convenience and costs, podophyllotoxin offers a favourable first-line approach to the burden placed by HPV infection on the health care system today. By minimising the number of appointments at the clinic for treatment of this often recalcitrant disease, and being able to offer the patient different formulations of podophyllotoxin, namely cream or solution, the compliance will probably if not certainly increase.

We thank Dr A Siboulet for his help in recruiting patients.

1 Kinghorn GR, McMillan A, Mulcahy F, Drake A, Lacey C, Bingham JS. An open, comparative, study of the efficacy of $0.5 \%$ podophyllotoxin lotion and $25 \%$ podophylcacy of $0.5 \%$ podophyllotoxin lotion and $25 \%$ podophyllotoxin solution in the treatment of condylomata 4:194-9.
2 von Krogh G. Topical treatment of penile condylomata acuminata with podophyllin, podophyllotoxin and acuminata with podophyllin, podophylloto

3 williams NR. Absence from work due to treatment fo genital warts. F Soc Occupational Med 1991;41:117-8.

4 von Krogh G. Penile condylomata acuminata: an experimental model for evaluation of topical self-treatmen with $0.5 \%-1.0 \%$ ethanol preparations of podophyllotoxin for three days. Sex Transm Dis 1981;8:179-86.

5 Beutner KR, von Krogh G. Current status of podophyllotoxin for the treatment of genital warts. Semin Dermato 1990;9:148-51.

6 Greenberg $M D$, Rutledge LH, Reid R, Berman NR, Precop SL, Elswick RK. A double-blind randomized trial of $0.5 \%$ podofilox and placebo for the treatment of

7 Mazurkiewicz W, Jablonska S. Comparison between the therapeutic efficacy of $0.5 \%$ podophyllotoxin preparations and the $20 \%$ podophyllin ethanol solution in condylomata acuminata. Hautkrankheiten 1986;61: condylom

8 Reynold M, Murphy M, Waugh MA, Lacy CJN. An audit of treatment of genital warts: opening the feedback loop. Int $₹$ STD AIDS 1993;4:226-31.

9 Strand A, Rylander E, Evander M, Wadell G. Genita human papillomavirus infection among patients attending an STD clinic. Genitourin Med 1993;69:446-9.

10 Lassus A. Comparison of podophyllotoxin and podophyllin in the treatment of genital warts. Lancet 1987; ii: $512-3$.

11 von Krogh G, Hellberg D. Self-treatment using a $0.5 \%$ podophyllotoxin cream of external genital condylomata podophyllotoxin cream of external genital condylomat 